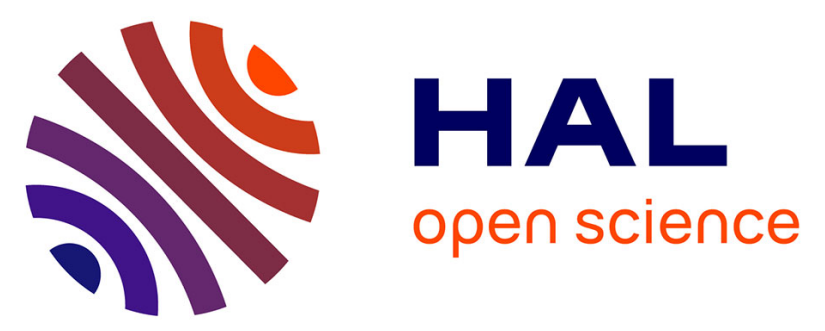

\title{
Oxidation of a silicon nitride-titanium nitride composite: Microstructural investigations and phenomenological modeling
}

F Deschaux-Beaume, Thierry Cutard, N Frety, Christophe Levaillant

\section{- To cite this version:}

F Deschaux-Beaume, Thierry Cutard, N Frety, Christophe Levaillant. Oxidation of a silicon nitridetitanium nitride composite: Microstructural investigations and phenomenological modeling. Journal of the American Ceramic Society, 2002, 85 (7), pp.1860-1866. 10.1111/j.1151-2916.2002.tb00365.x . hal-01714942

\author{
HAL Id: hal-01714942 \\ https://hal.science/hal-01714942
}

Submitted on 6 Nov 2019

HAL is a multi-disciplinary open access archive for the deposit and dissemination of scientific research documents, whether they are published or not. The documents may come from teaching and research institutions in France or abroad, or from public or private research centers.
L'archive ouverte pluridisciplinaire HAL, est destinée au dépôt et à la diffusion de documents scientifiques de niveau recherche, publiés ou non, émanant des établissements d'enseignement et de recherche français ou étrangers, des laboratoires publics ou privés. 


\title{
Oxidation of a Silicon Nitride-Titanium Nitride Composite: Microstructural Investigations and Phenomenological Modeling
}

\author{
Frédéric Deschaux-Beaume, ${ }^{\dagger}$ Thierry Cutard,${ }^{\dagger}$ Nicole Fréty, ${ }^{\ddagger}$ and Christophe Levaillant ${ }^{\dagger}$ \\ Ecole des Mines d'Albi, Campus Jarlard, 81000 Albi, France \\ Université de Montpellier II, LPMC, 34092 Montpellier, France
}

The high-temperature oxidation of a silicon nitride-titanium nitride $\left(\mathrm{Si}_{3} \mathrm{~N}_{4}-\mathrm{TiN}\right)$ composite has been investigated via scanning electron microscopy and energy-dispersive and wavelength-dispersive spectrometry. At $1150^{\circ} \mathrm{C}$, the oxidation of both the silicon nitride and titanium nitride phases takes place. Several oxidation processes act simultaneously and/or successively. First, the oxidation of the titanium nitride occurs and leads to the formation of a continuous titanium oxide $\left(\mathrm{TiO}_{2}\right)$ crystal layer at the surface. Next, the $\mathrm{TiO}_{2}$ formation takes place in the sublayer at the same time as the $\mathrm{Si}_{3} \mathrm{~N}_{4}$ oxidation. The oxidation of this last phase leads to the formation of vitreous silica $\left(\mathrm{SiO}_{2}\right)$. For long a duration of oxidation ( $>50 \mathrm{~h}$ ), a continuous layer of $\mathrm{SiO}_{2}$ is formed under the outer $\mathrm{TiO}_{2}$ scale. Large pores grow in this layer and deform the outer oxide layers, whereas the oxidation occurs in the material. Based on these results and bibliographical data, a phenomenological model is proposed to describe the stages of the high-temperature oxidation of $\mathrm{Si}_{3} \mathbf{N}_{4}-\mathrm{TiN}$ materials.

\section{Introduction}

$\mathrm{C}$ ERAMICS that are based on silicon nitride $\left(\mathrm{Si}_{3} \mathrm{~N}_{4}\right)$ combine a set of properties that make them good candidates for hightemperature structural applications. With their low-density, lowthermal expansion coefficient, high hardness, high-corrosion resistance and high-mechanical properties, these ceramics are more appropriate than metals for such applications. However, the development of engineering ceramic components is impeded by two major factors. The first deals with lifetime and reliability problems, which are difficult to solve; the second concerns the high cost of fine ceramic parts. Electroconductive ceramics, such as silicon nitride-titanium nitride $\left(\mathrm{Si}_{3} \mathrm{~N}_{4}-\mathrm{TiN}\right)$ composites, may offer new opportunities because they combine the high performance of $\mathrm{Si}_{3} \mathrm{~N}_{4}$-based ceramics with machinability by electrodischarge machining (EDM). ${ }^{1-5}$ However, the addition of a titanium nitride phase strongly influences the oxidation behavior of the $\mathrm{Si}_{3} \mathrm{~N}_{4}$ ceramic at high temperatures. The oxidation mechanisms of both titanium nitride and $\mathrm{Si}_{3} \mathrm{~N}_{4}$ ceramics have been widely studied and described. ${ }^{6,7}$ These results lay the foundations for understanding the high-temperature behavior of $\mathrm{Si}_{3} \mathrm{~N}_{4}-\mathrm{TiN}$ composites, which have received little study thus far. ${ }^{8-11}$

D. P. Butt-contributing editor

†Ecole des Mines d'Albi.

Universite' de Montpellier II, LPMC.
The oxidation of titanium nitride to rutile or titanium oxide $\left(\mathrm{TiO}_{2}\right)$ starts between $500^{\circ}-600^{\circ} \mathrm{C}$, according to this reaction: ${ }^{6,11-16}$

$$
\mathrm{TiN}(s)+\mathrm{O}_{2}(g) \rightleftarrows \mathrm{TiO}_{2}(s)+\frac{1}{2} \mathrm{~N}_{2}(g)
$$

Concerning TiN, oxidation is often controlled via oxygen diffusion through $\mathrm{TiO}_{2}{ }^{6,8,15,16}$ This is especially observed at $<1000^{\circ} \mathrm{C}$. At higher temperatures, the rate-controlling mechanism is not clearly identified; however, the contribution of a cationic diffusion of titanium should not be excluded. ${ }^{12,13}$ Indeed, after oxidation, outward growth of $\mathrm{TiO}_{2}$ is observed and porosity is sometimes detected under the rutile layer. This indicates that the outward diffusion of titanium is very fast. ${ }^{9,11,14}$ This can be confirmed by the outward growth of rutile crystals, which is observed during the oxidation of titanium and titanium-based alloys and is attributed to the rapid diffusion of titanium through $\mathrm{TiO}_{2} \cdot{ }^{17,18}$ Nevertheless, a direct transposition of these results to titanium nitride materials must be done carefully because of the presence of nitrogen. Indeed, it has been observed that titanium and titanium-based alloys oxidize much slower in air than they do in pure oxygen. ${ }^{19}$

The oxidation of $\mathrm{Si}_{3} \mathrm{~N}_{4}$-based ceramics is also complex..$^{20-26}$ Oxidation of pure silicon nitride (powder or chemical vapor deposition (CVD) deposit) leads to the formation of a $\mathrm{SiO}_{2}$ amorphous layer on the surface (reaction (2)), separated from the core material by a thin layer of a graded suboxide $\left(\mathrm{SiN}_{x} \mathrm{O}_{y}\right)^{27-29}$ or a crystalline oxynitride $\left(\mathrm{Si}_{2} \mathrm{~N}_{2} \mathrm{O}\right):{ }^{21-23}$

$$
\mathrm{Si}_{3} \mathrm{~N}_{4}(s)+3 \mathrm{O}_{2}(g) \rightleftarrows 3 \mathrm{SiO}_{2}(s)+2 \mathrm{~N}_{2}(g)
$$

Oxidation is then controlled by the diffusion of oxygen through the $\mathrm{SiO}_{2}$ and oxynitride layers. ${ }^{28}$ Sintered silicon nitride generally oxidizes more quickly than silicon nitride powders or CVD deposits. ${ }^{30-34}$ This is related to the presence of an intergranular phase originating from sintering additives $\left(\mathrm{Y}_{2} \mathrm{O}_{3}\right.$ and $\left.\mathrm{Al}_{2} \mathrm{O}_{3}\right)$. Some species (yttrium, aluminum, and oxygen) are more mobile in this phase than in $\mathrm{Si}_{3} \mathrm{~N}_{4}$ at a high temperature. Oxidation is then the result of the inward diffusion of oxygen through the oxide layer and the outward diffusion of yttrium and aluminum species through the intergranular phase. Oxidation kinetics, therefore, depends on the composition and amount of the intergranular phase. ${ }^{32}$

The oxidation behavior of $\mathrm{Si}_{3} \mathrm{~N}_{4}-\mathrm{TiN}$ composites is equally complex because the various mechanisms previously presented can act simultaneously. In the $600^{\circ}-1000^{\circ} \mathrm{C}$ temperature range, the titanium nitride phase essentially oxidizes; whereas at higher temperatures, the oxidation of the two phases takes place at the same time.$^{8,9,11}$ The oxidation process is therefore the result of the diffusion of various species (oxygen, titanium, aluminum, and yttrium) in various phases (such as $\mathrm{TiN}, \mathrm{TiO}_{2}, \mathrm{SiO}_{2}$, and glassy phases) and new chemical reactions.

The present work is a contribution to the study of the oxidation of $\mathrm{Si}_{3} \mathrm{~N}_{4}-\mathrm{TiN}$ composites. A detailed microstructural study of the oxidation in air of a commercial $\mathrm{Si}_{3} \mathrm{~N}_{4}-\mathrm{TiN}$ composite at $1150^{\circ} \mathrm{C}$ is presented. Based on scanning electron microscopy (SEM) 
observations, energy-dispersive spectrometry (EDS) measurements, wavelength-dispersive spectrometry (WDS) measurements, and literature data, a phenomenological oxidation model is proposed to describe the complex oxidation behavior of such composites at $>1000^{\circ} \mathrm{C}$.

\section{Experimental Procedures}

\section{(1) Material}

A commercial $\mathrm{Si}_{3} \mathrm{~N}_{4}-\mathrm{TiN}$ composite that has been retained in the present work was fabricated by Norton Desmarquest Fine Ceramics following a conventional processing route for fine ceramics, starting from a mixture of $\mathrm{Si}_{3} \mathrm{~N}_{4}$ and TiN powders in equivalent weight proportions. A few percent of high purity $\mathrm{Y}_{2} \mathrm{O}_{3}$ and $\mathrm{Al}_{2} \mathrm{O}_{3}$ powders was added to the initial mixture. Alumina acts as a sintering aid because it increases the $\mathrm{Si}_{3} \mathrm{~N}_{4}$ solubility in the liquid phase at the sintering temperature. ${ }^{35}$ The presence of $\mathrm{Y}_{2} \mathrm{O}_{3}$ leads to an increase in the high-temperature mechanical properties of the intergranular phase in $\mathrm{Si}_{3} \mathrm{~N}_{4}$-based materials. ${ }^{36}$ After a cold isostatic compaction step, the composite is densified during sintering at $1800^{\circ} \mathrm{C}$ under a nitrogen atmosphere.

Figure 1 is a SEM micrograph showing the microstructure of the material after sintering, which consists of titanium nitride and silicon nitride grains and an oxide-rich intergranular phase. Silicon nitride grains exhibit an acicular form characteristic of the $\beta-\mathrm{Si}_{3} \mathrm{~N}_{4}$ structure. The diameter of the grains does not exceed $0.5 \mu \mathrm{m}$. Titanium nitride grains are homogeneously distributed in the composite, and their size ranges from $0.5-8 \mu \mathrm{m}$. The titanium nitride phase forms a continuous network, as previously shown by the measurement of the electrical conductivity of such $\mathrm{Si}_{3} \mathrm{~N}_{4}-\mathrm{TiN}$ composites. ${ }^{4}$

\section{(2) Methods}

Samples $(10 \mathrm{~mm} \times 4 \mathrm{~mm} \times 2 \mathrm{~mm})$ were machined using EDM, then polished with diamond pastes down to the $1 \mu \mathrm{m}$ grade. Various samples were oxidized at $1150^{\circ} \mathrm{C}$ in air for a duration of $1,2,5,10,20,100,150$, and $200 \mathrm{~h}$, respectively. The microstructures of the oxidized samples have been characterized by SEM (Model XL30, Philips, Eindhoven, Netherlands) performed on both the external surfaces and cross sections. Complementary analytical investigations have been performed by energydispersive spectrometry (Model DX-4, EDAX International, Mahwah, NJ) and wavelength-dispersive spectrometry (Model SX50, Cameca Instruments, Courbevoie Cedex, France) to get elemental profiles across oxidized layers.

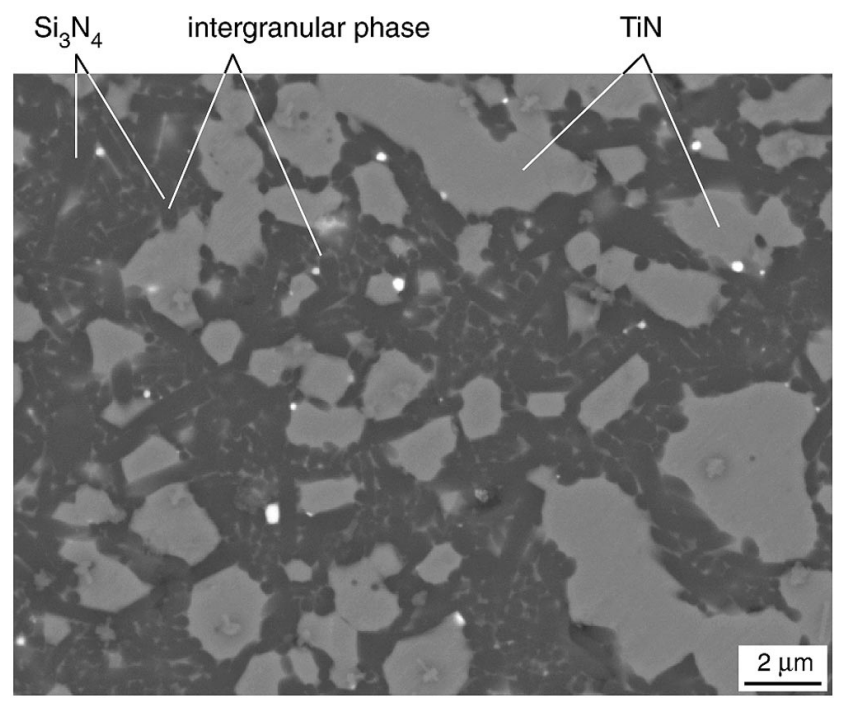

Fig. 1. Backscattered SEM micrograph of a cross section of the assintered $\mathrm{Si}_{3} \mathrm{~N}_{4}-\mathrm{TiN}$ composite.

\section{Results}

Figure 2 shows a backscattered SEM micrograph and corresponding elemental analyses of the polished cross section of a sample that has been oxidized for $100 \mathrm{~h}$. A $50 \mu \mathrm{m}$ thick oxidized area can be observed in which large microstructural modifications have taken place. The morphology of this oxidized area is similar to that observed by Bellosi et al. ${ }^{8}$ and by Gogotsi et al..$^{9,11}$ on similar materials. Three layers can be distinguished in this area from the surface to the nonoxidized material core.

The first layer (layer 1) is composed primarily of large lightgray crystals, which can be identified as a $\mathrm{TiO}_{2}$ phase, according to the WDS analysis. The structure and texture of $\mathrm{TiO}_{2}$ crystals can be seen on a top view of the sample surface (Fig. 3). The second layer (layer 2) is composed of isolated $\mathrm{TiO}_{2}$ crystals and a continuous dark-gray glassy phase. This second phase is characterized by a silicon/oxygen atomic ratio of $\sim 1 / 2$, which indicates a stoichiometry close to $\mathrm{SiO}_{2}$. This phase is the reaction product of the $\mathrm{Si}_{3} \mathrm{~N}_{4}$ oxidation. The second layer contains large spherical pores with diameters of 2-20 $\mu \mathrm{m}$. Small white or dark gray grains also can be seen in this layer. These phases are aluminum- and/or yttrium-rich and will be discussed in more detail later. The third layer (layer 3 ) exhibits a more complex microstructure consisting of several phases and porosity. The oxidation front (I3) that separates this third oxidation layer from the core material can be

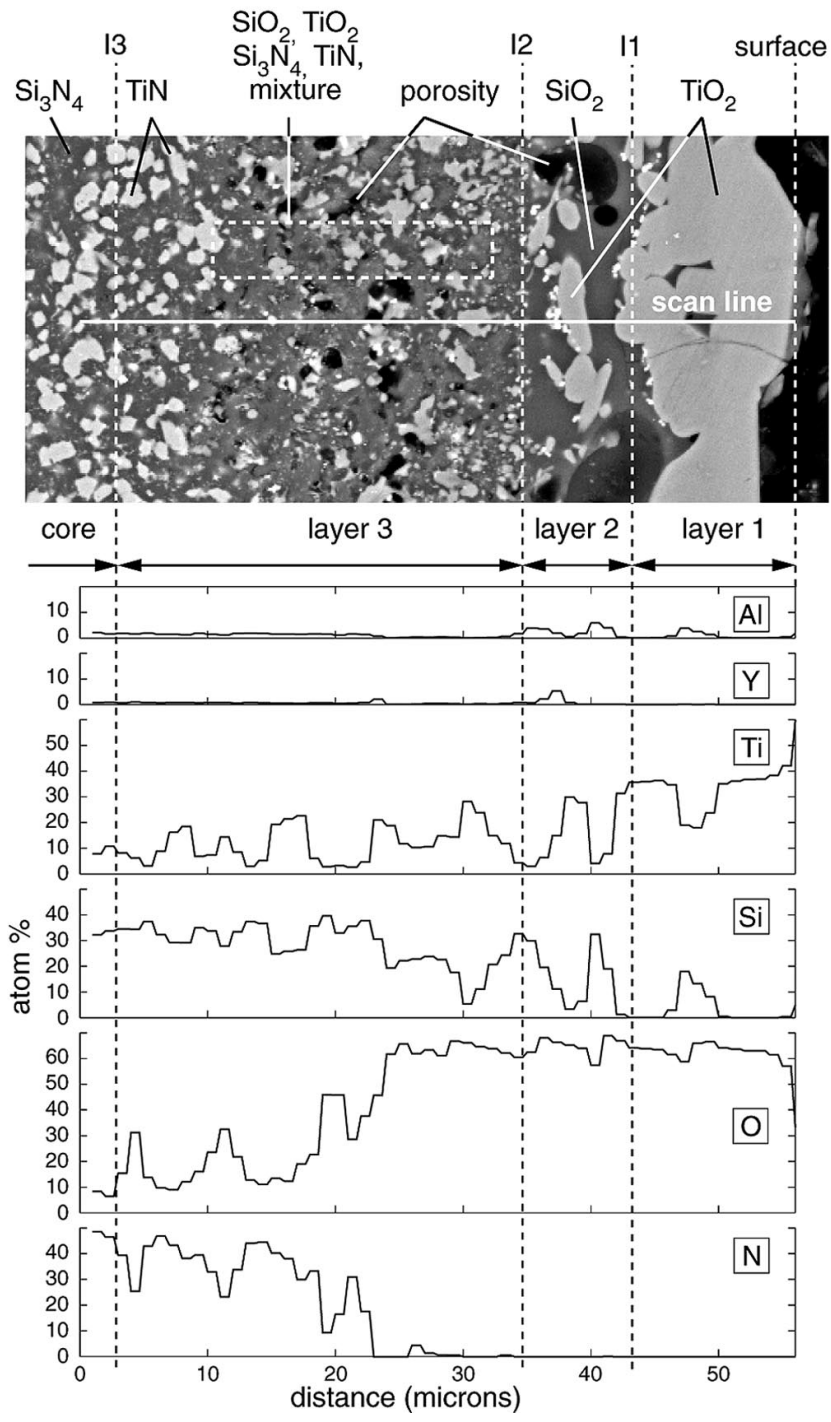

Fig. 2. Backscattered SEM micrograph of a cross section of the $\mathrm{Si}_{3} \mathrm{~N}_{4}$ TiN composite after $100 \mathrm{~h}$ at $1150^{\circ} \mathrm{C}$ in air. Graphs indicate the variations of the atomic contents measured by WDS along the continuous white line. 


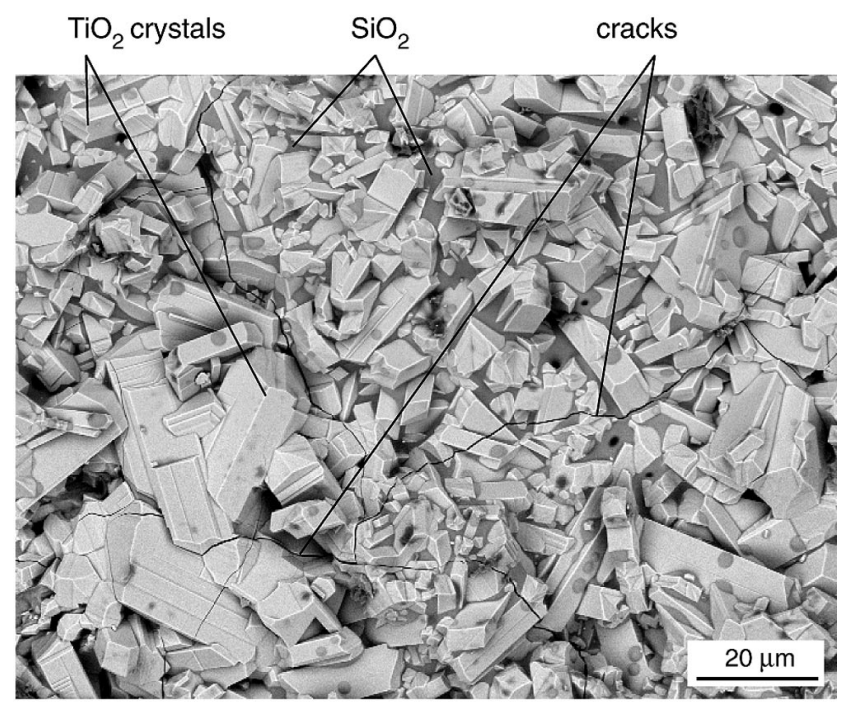

Fig. 3. Top view of the external surface of the $\mathrm{Si}_{3} \mathrm{~N}_{4}-\mathrm{TiN}$ composite after $100 \mathrm{~h}$ at $1150^{\circ} \mathrm{C}$ in air (SEM micrograph).

clearly distinguished and is characterized by a significant roughness. Microstructural gradients are observed on SEM micrographs and on WDS results in this layer. From the oxidation front (I3) to the interface (I2) between layers 2 and 3, a trend toward increasing is observed for both the titanium and oxygen contents while a trend toward decreasing is measured for the silicon and nitrogen contents. This indicates that titanium diffusion toward the surface is rapid, resulting in the formation of titanium oxide in this sublayer. The simultaneous observation of the SEM micrograph and of the WDS measurements (Fig. 2) reveals the transformations of the initial titanium nitride network. Close to the I 2 interface, the initial titanium nitride grains have been replaced primarily by $\mathrm{TiO}_{2}$ crystals; whereas in the center of the layer and close to the oxidation front (I3 interface) they have been replaced primarily by porosity, caused by the outward diffusion of titanium. A gradual evolution can be supposed between the two interfaces in this network. The presence of nitrogen in the third layer indicates that material is only partially oxidized in this area. According to data in the literature, $\mathrm{Si}_{3} \mathrm{~N}_{4}$ is more oxidation resistant than titanium nitride. ${ }^{8,9,11}$ We can then suppose that the remaining nitrogen results from unoxidized $\mathrm{Si}_{3} \mathrm{~N}_{4}$, only a part of this phase being oxidized in this sublayer.

Based on this hypothesis, the proportions of the major phases that constitute the entire oxidized area have been calculated. Such calculations have been performed from the line scan results with the following assumptions:

(1) The oxidized area of the composite consists of the following four phases: $\mathrm{Si}_{3} \mathrm{~N}_{4}, \mathrm{TiN}, \mathrm{SiO}_{2}$, and $\mathrm{TiO}_{2}$. Other phases are supposed to be present in negligible proportions.

(2) For high oxygen content $([\mathrm{O}]>2[\mathrm{Ti}]$, given in atomic percent), all of the titanium is considered to be associated with oxygen and forms stoichiometric $\mathrm{TiO}_{2}$. The remaining oxygen forms stoichiometric $\mathrm{SiO}_{2}$.

(3) For low oxygen contents ([O] $<2$ [Ti], given in atomic percent), only stoichiometric $\mathrm{TiO}_{2}$ is formed and the remaining phases are titanium nitride and $\mathrm{Si}_{3} \mathrm{~N}_{4}$.

Despite these simplifying assumptions, the results of these calculations (Fig. 4) are in good agreement with the SEM observations. They confirm the high $\mathrm{TiO}_{2}$ content in layer 1 , the high silica content in layer 2 , the regular decrease in the $\mathrm{TiO}_{2}$ content, and the regular increase in the $\mathrm{Si}_{3} \mathrm{~N}_{4}$ content from the I2 interface to the $\mathrm{I} 3$ oxidation front.

Figure 5 shows the evolution of the morphology of the oxidized surface according to the oxidation duration. The diffusion of titanium toward the surface occurs very rapidly at $1150^{\circ} \mathrm{C}$, as is shown by the continuous $\mathrm{TiO}_{2}$ surface layer and the sublayer

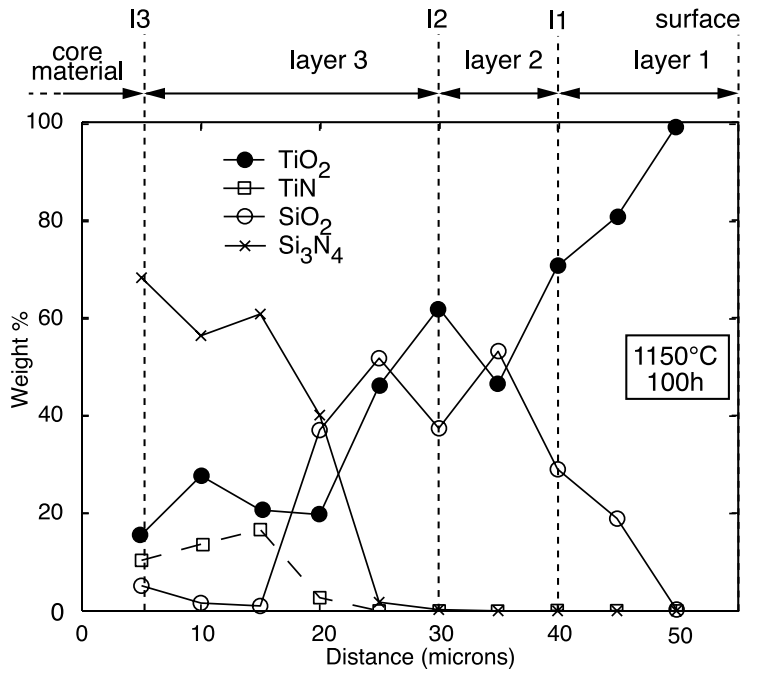

Fig. 4. Phase content variations in the oxidized area, along the scan line of Fig. 2 and calculated from WDS measurements.

porosity, already formed after $1 \mathrm{~h}$ of oxidation. The growth of layer 1 (the surface layer) is rapid at the beginning of oxidation, then slows to reach a thickness of $\sim 5-10 \mu \mathrm{m}$ after $10 \mathrm{~h}$ and remains constant. For oxidation times $>50 \mathrm{~h}$, the $\mathrm{TiO}_{2}$ surface layer contains numerous cracks (Figs. 3 and 5).

After $\sim 100 \mathrm{~h}$ of oxidation, a continuous layer of $\mathrm{SiO}_{2}$ (layer 2) containing large cavities starts forming under and around the surface $\mathrm{TiO}_{2}$ crystals.

The respective thickness of the three oxidation layers varies as a function of the oxidation duration. All thicknesses were measured for each oxidation duration on SEM micrographs of polished cross sections. Results are given in Fig. 6. They show the rapid growth of layer $1\left(\mathrm{TiO}_{2}\right.$-rich) during the first oxidation hours. This layer reaches a quasi-constant thickness after $\sim 10 \mathrm{~h}$ at $1150^{\circ} \mathrm{C}$. Layer 3 also grows rapidly during the initial stage of oxidation, but its thickness continues to increase up to $50 \mathrm{~h}$. At $>50$ oxidation hours, stabilization is observed. A delay is observed before layer 2 appears and begins growing. Indeed, this layer is observed only for oxidation times $>20 \mathrm{~h}$, and then its thickness continuously increases. For long duration (up to $200 \mathrm{~h}$ ), it becomes difficult to separate layers 1 and 2 because of morphology changes that occur in the silica-rich layer (layer 2). As can be seen in Fig. 7, the silica phase has grown and/or flowed into the $\mathrm{TiO}_{2}$ layer and the external surface of the oxidized composite is mainly composed of rounded $\mathrm{TiO}_{2}$ crystals embedded in $\mathrm{SiO}_{2}$-rich phase, between which large pores form. WDS measurements performed along the white line of Fig. 7 show the presence of aluminum in this phase with an aluminum/silicon atomic ratio close to $1 / 4$. This indicates the diffusion of aluminum toward the surface as previously observed in the case of the oxidation of $\mathrm{Si}_{3} \mathrm{~N}_{4}$ ceramics with an intergranular glassy phase. ${ }^{30}$ This intergranular phase reacts with silica to form stable compounds or dissolves into silica. The resulting chemical gradient in the intergranular phase leads to a migration of the aluminum and yttrium species toward the surface. This can also explain the presence of small white crystals characterized by a high yttrium content and the presence of dark-gray crystals characterized by a high aluminum content (Fig. 7). Similar phases have previously been observed and identified as oxidation products of $\mathrm{Si}_{3} \mathrm{~N}_{4}$-based ceramics, which concern yttrium silicates or titanates $\left(\mathrm{Y}_{2} \mathrm{SiO}_{5}, \mathrm{Y}_{2} \mathrm{Si}_{2} \mathrm{O}_{7}, \mathrm{Y}_{2} \mathrm{Ti}_{2} \mathrm{O}_{7}\right)$ for the first ones and mullite crystals $\left(3 \mathrm{Al}_{2} \mathrm{O}_{3} \cdot 2 \mathrm{SiO}_{2}\right)$ for the second ones. ${ }^{8-10,28,29}$

\section{Oxidation Modeling}

The oxidation behavior of the studied $\mathrm{Si}_{3} \mathrm{~N}_{4}-\mathrm{TiN}$ composite at $>1000^{\circ} \mathrm{C}$ is complex because of several processes that take place simultaneously. A phenomenological oxidation model is proposed 


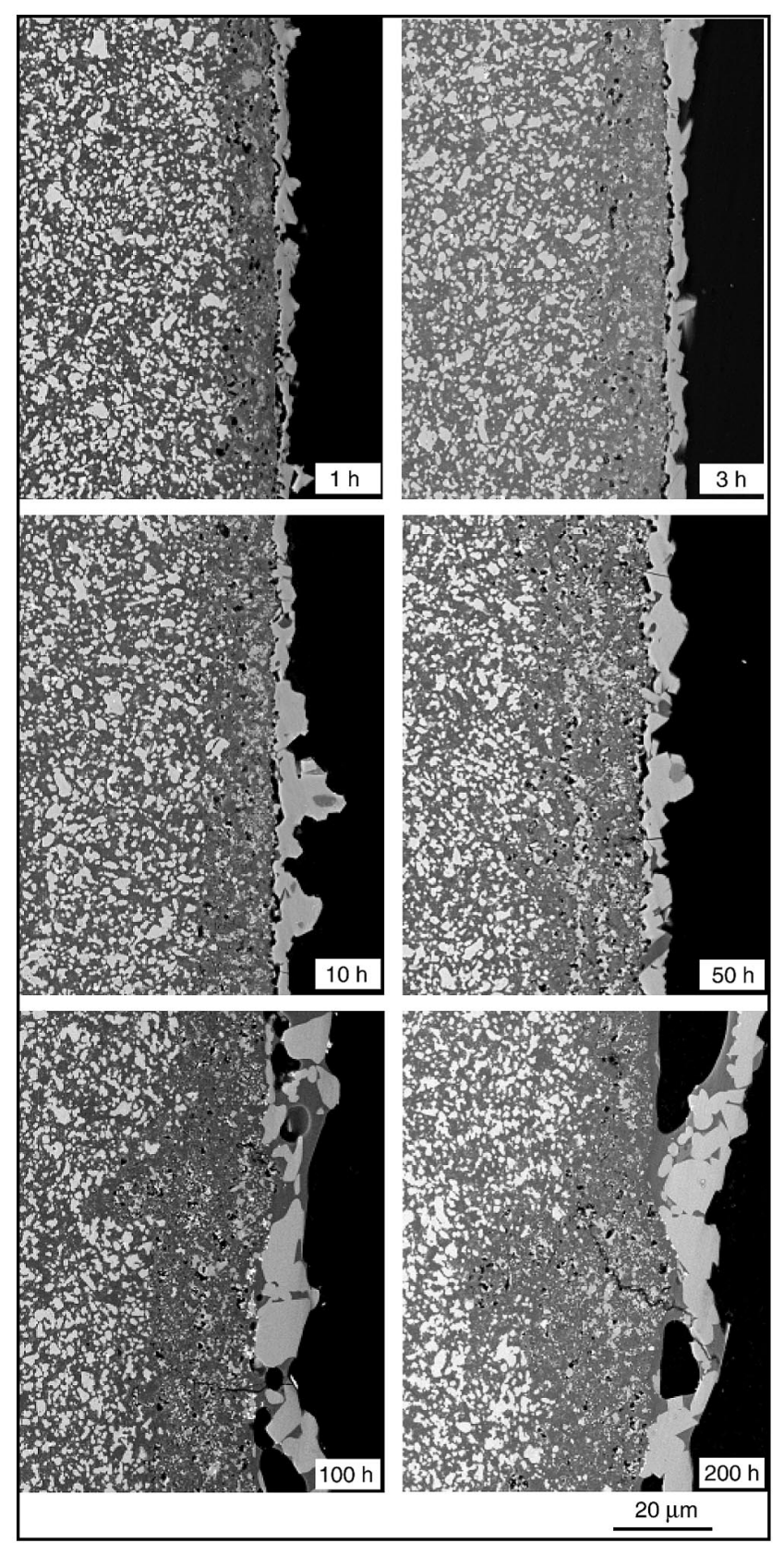

Fig. 5. Backscattered SEM micrographs of cross sections of the $\mathrm{Si}_{3} \mathrm{~N}_{4}-$ TiN composite after different oxidation durations at $1150^{\circ} \mathrm{C}$ in air.

for $\mathrm{Si}_{3} \mathrm{~N}_{4}-\mathrm{TiN}$ composites in which the TiN content is high enough to constitute a continuous network at $1150^{\circ} \mathrm{C}$. The model is based on the results of this experimental study and on bibliographical data.

Four stages can be distinguished in the oxidation process of these $\mathrm{Si}_{3} \mathrm{~N}_{4}$-based materials (Fig. 8).

\section{(1) Stage 1}

During the first oxidation stage (Fig. 8(a)), which occurs rapidly during the first oxidation hours, titanium nitride particles close to the surface are oxidized to $\mathrm{TiO}_{2}$ according to reaction (1). The growth of the oxide layer covering the titanium nitride particles is controlled by the diffusion of titanium through $\mathrm{TiO}_{2}$, leading to a lateral growth of rutile crystals that progressively covers the entire surface. This mechanism is not in agreement with the general theory for the oxidation of titanium nitride, which considers that the process is controlled by anionic diffusion..$^{6,8,15,16}$ However, it

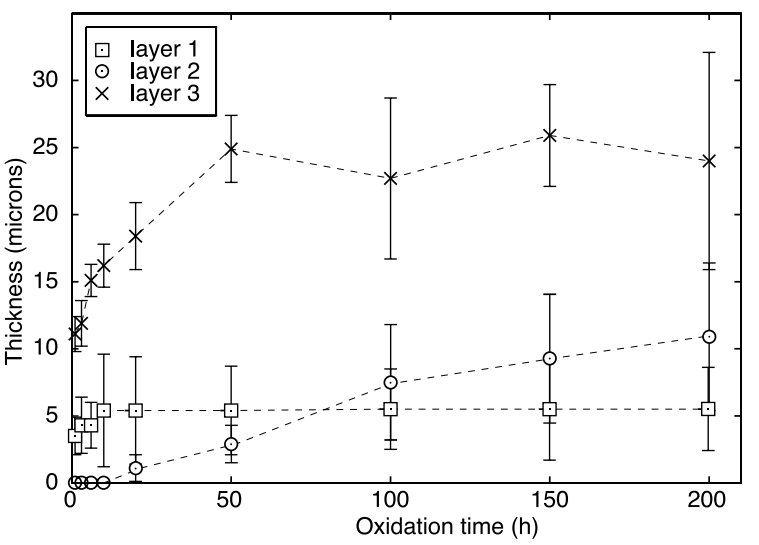

Fig. 6. Evolution of the respective thickness of layers 1, 2, and 3 of the oxidized area as a function of the oxidation duration at $1150^{\circ} \mathrm{C}$ in air.

is admitted that oxygen diffuses via short-circuit diffusion paths in polycrystalline rutile; whereas in single-crystal rutile, the titanium diffusion is faster than the oxygen diffusion ${ }^{6,17}$ In the case of the $\mathrm{Si}_{3} \mathrm{~N}_{4}-\mathrm{TiN}$ composite, the titanium nitride particles are small $(0.5-8 \mu \mathrm{m})$. During the first oxidation stage, a single-crystal of rutile could be formed on the surface of each outer titanium nitride particle. That should explain the faster diffusion of titanium toward the surface, which was observed in our experiments. Given the nonstoichiometry of $\mathrm{TiO}_{2}$, other explanations are possible involving point defects and possible effects of impurity. The oxidation of
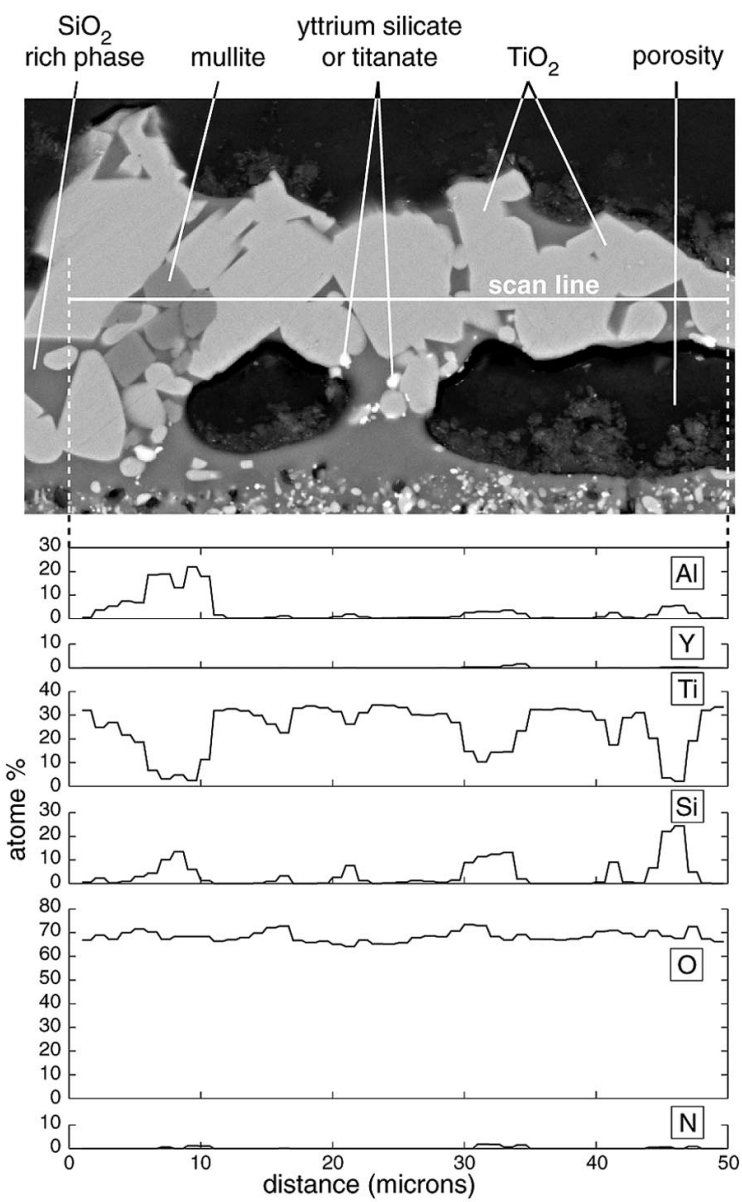

Fig. 7. Backscattered SEM micrograph of a cross section of the $\mathrm{Si}_{3} \mathrm{~N}_{4}$ TiN composite after $200 \mathrm{~h}$ at $1150^{\circ} \mathrm{C}$ in air. Graphs indicate the variations of the atomic contents measured by WDS along the continuous white line. 

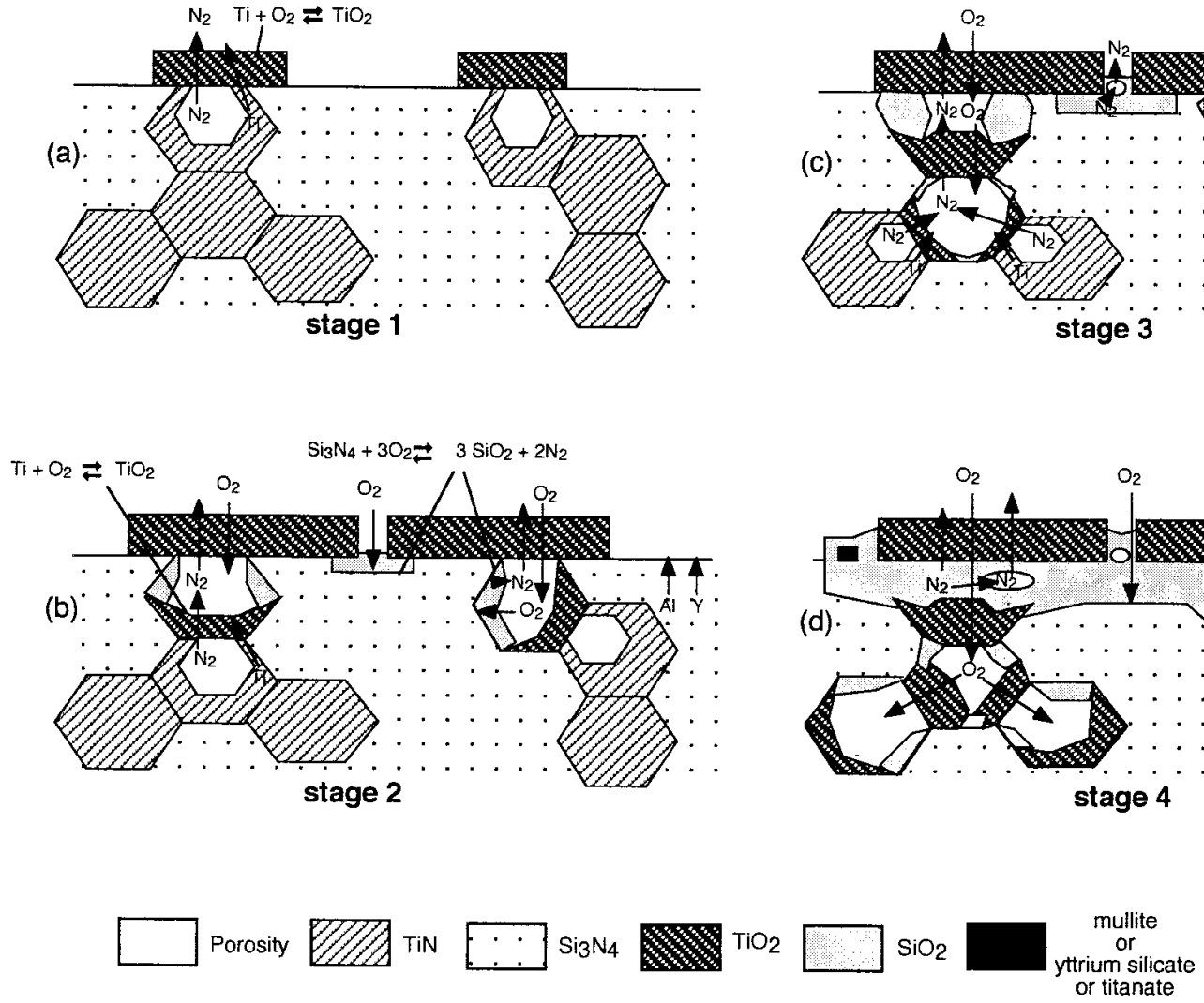
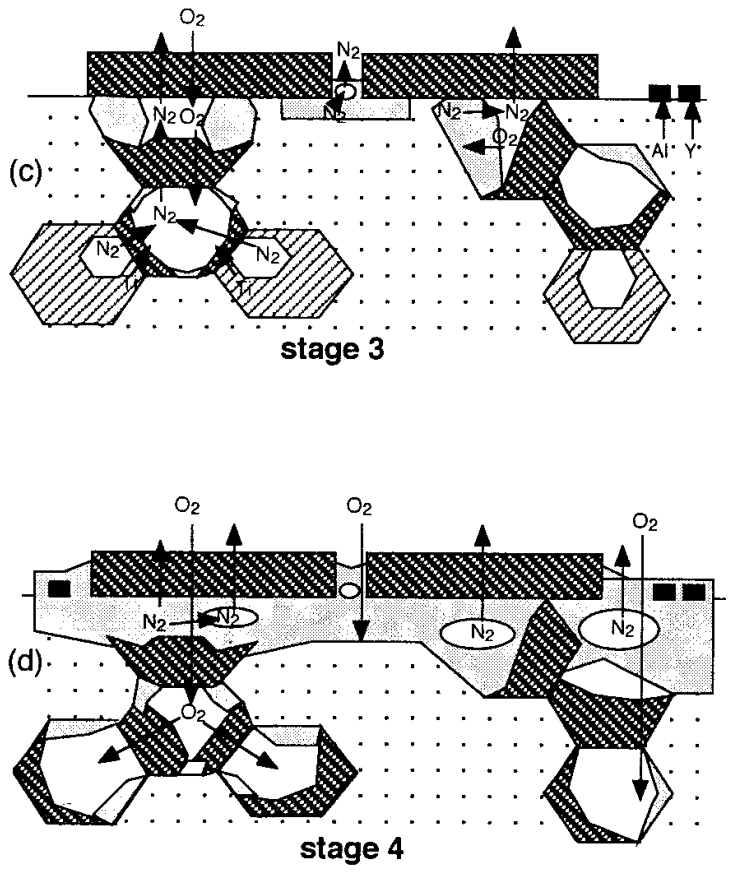

or titanate

Fig. 8. Schematic representation of the $\mathrm{Si}_{3} \mathrm{~N}_{4}-\mathrm{TiN}$ composite oxidation mechanisms. Four successive stages can be distinguished. In stage 1, the oxidation is controlled by the diffusion of titanium toward the surface, through the $\mathrm{TiO}_{2}$ layer. In stage 2, the oxidation is controlled by the diffusion of oxygen through the successive $\mathrm{TiO}_{2}$ layers separated by porosity. The third stage is then in a transient mode, resulting from several mechanisms acting simultaneously. In stage 4 , the oxidation is controlled by the diffusion of molecular oxygen through the $\mathrm{SiO}_{2}$ layer.

the silicon nitride phase, which is slower than that of the titanium nitride phase, does not act significantly during this stage.

At the end of this first stage, the material surface is almost entirely covered with $\mathrm{TiO}_{2}$. The titanium impoverishment in the titanium nitride particles close to the surface (because of the outward diffusion of titanium) causes an increase in the nitrogen dissociation partial pressure, which is then released. Pores, formed by the coalescence of the vacancies induced by the motion of titanium and nitrogen, appear in the sublayer, into the site of the initial titanium nitride particles. This porosity can contain molecular nitrogen, which can also diffuse toward the surface.

\section{(2) Stage 2}

The formation and growth of porosity in the sublayer reduce the available surface for titanium diffusion, from inner titanium nitride toward the $\mathrm{TiO}_{2}$ layer and the atmosphere. The diffusion of titanium then slows during the first oxidation stage. On the other hand, oxygen can diffuse toward the material core through porosity in a molecular form. Assuming that oxygen diffusion through the porosity is faster than through the rutile, the diffusion rate of oxygen remains constant when porosity grows. The inward diffusion of oxygen then becomes faster than the outward diffusion of titanium. During the second oxidation stage, inner titanium nitride particles are oxidized, caused by the oxygen having diffused in the sublayer porosity. Because the titanium diffusion is faster than oxygen diffusion through the newly formed rutile crystals, the oxidation reaction takes place at the $\mathrm{TiO}_{2} / \mathrm{O}_{2}$ interfaces,. The growth of these new inner $\mathrm{TiO}_{2}$ crystals partially fills the porosity in the outer area of the sublayer, and at the same time, the titanium migration leads to the formation of new porosity close to the oxidation front that separates the core material from the oxidized one. Oxygen can then reach these new pores, leading to a gradual internal oxidation.

During this stage, the silicon nitride phase begins to oxidize into silica, according to reaction (2). No oxynitride phase has been identified in the oxide layer, as was observed between $\mathrm{SiO}_{3}$ and $\mathrm{Si}_{3} \mathrm{~N}_{4}$ phases, during oxidation of pure silicon nitride. ${ }^{21-23,27-29}$ However, the oxynitride phase has rarely been observed in the case of the oxidation of silicon nitride with an intergranular phase..$^{30-34}$ The data of the present paper does not provide sufficient information either to prove or disprove whether an oxynitride phase is present. This model does not depend on the presence of an oxynitride phase. Oxidation of the $\mathrm{Si}_{3} \mathrm{~N}_{4}$ phase is, therefore, controlled by the diffusion of oxygen through $\mathrm{SiO}_{2}$.

The oxidation process takes place in the outer surface but also through internal porosity, which contains oxygen. The diffusion of oxygen through silica is very slow in comparison with the diffusion through $\mathrm{TiO}_{2}{ }^{8,9,11}$ Thus, the main mechanism controlling the oxidation rate during this stage is the diffusion of oxygen through the surface and inner $\mathrm{TiO}_{2}$ crystals, separated by porosity. Nevertheless, the oxidation of the $\mathrm{Si}_{3} \mathrm{~N}_{4}$ phase can slightly modify the kinetics, particularly at higher temperatures (at $\sim 1200^{\circ} \mathrm{C}$ ).

\section{(3) Stage 3}

The transformation of $\mathrm{Si}_{3} \mathrm{~N}_{4}$ into $\mathrm{SiO}_{2}$ leads to a $96 \%$ molar volume increase, which can create internal stresses. After several hours of oxidation, the quantity of silica begins to be important, and growth stresses associated with this oxidation process increase. Silica, which has a viscous behavior at $>1000^{\circ} \mathrm{C}$, flows under these stresses and fills the available spaces, i.e., the porosity and the spaces between the surface $\mathrm{TiO}_{2}$ crystals. The nitrogen released by the oxidation reaction diffuses toward the surface and/or forms gas bubbles in silica (Fig. 8(c)). Bubbles can be 
formed under low nitrogen pressures in silica, as shown by Mieskowski et al. ${ }^{37}$ because of the low viscosity of the vitreous oxide. Yttrium and aluminum, initially present in the intergranular glassy phase, migrate toward the surface and are dissolved into silica or form mullite $\left(3 \mathrm{Al}_{2} \mathrm{O}_{3} \cdot 2 \mathrm{SiO}_{2}\right)$ and yttrium silicates and/or titanates. ${ }^{8-10,30,31}$

At the same time, the internal oxidation of the titanium nitride phase continues to occur in the core material, because of the oxygen having reached the pores. However, the available surface for oxygen diffusion through $\mathrm{TiO}_{2}$ crystals and porosity, toward inner titanium nitride particles, decreases with the growth and the flow of silica in the porosity of the upper area of the sublayer. Because oxygen diffusion through $\mathrm{SiO}_{2}$ is slower than through $\mathrm{TiO}_{2}$ and porosity, the oxidation of inner titanium nitride then slows down. During the third stage, which is a transient step, oxidation is controlled by two mechanisms. The oxidation of the $\mathrm{Si}_{3} \mathrm{~N}_{4}$ phase remains controlled by oxygen diffusion through $\mathrm{SiO}_{2}$, whereas titanium nitride oxidation is controlled by both oxygen diffusion through $\mathrm{TiO}_{2}$ and through $\mathrm{SiO}_{2}$, which progressively fills the porosity near the outer $\mathrm{TiO}_{2}$ crystals.

\section{(4) Stage 4}

When silica forms a continuous layer under the material surface (Fig. 8(d)), oxygen has to diffuse across this new layer to oxidize the inner titanium nitride and $\mathrm{Si}_{3} \mathrm{~N}_{4}$ phases. An oxidation deceleration is observed. The oxidation rate is then controlled during the fourth stage via the diffusion of oxygen through the $\mathrm{SiO}_{2}$ layer. The nitrogen, which is still released, diffuses toward the surface or forms gas bubbles that grow in silica and sometimes burst on the surface.

\section{Discussion}

The present oxidation model involves three major and successive oxidation modes. Each is controlled by a dominant diffusion mechanism. These three modes, described by the stages 1,2 , and 4 of the model, are separated by transient stages (such as stage 3 ). The rate of the dominant mechanism slows regularly as the oxidation duration increases, i.e., from step 1 to step 4 . The duration of each step depends strongly on the temperature level.

A microstructural discussion can be made regarding the three oxidation layers previously described (Figs. 2, 4, 5, and 6). The growth of each layer (Fig. 6) can be related to one of the three oxidation modes. Layer 1 consists primarily of $\mathrm{TiO}_{2}$ crystals. A continuous layer is formed for an oxidation duration as short as $1 \mathrm{~h}$ at $1150^{\circ} \mathrm{C}$. The growth of this layer stops after a few hours of oxidation. Its formation is related to the first oxidation mode (stage 1 ), which concerns the oxidation of titanium nitride in $\mathrm{TiO}_{2}$ controlled by the diffusion of titanium through $\mathrm{TiO}_{2}$. Layer 3 consists of $\mathrm{TiO}_{2}$ and partially oxidized $\mathrm{Si}_{3} \mathrm{~N}_{4}$. Its growth also occurs rapidly at the beginning of oxidation, slows down after $\sim 10$ $\mathrm{h}$ at $1150^{\circ} \mathrm{C}$, and then stabilizes after $50 \mathrm{~h}$. The growth of layer 3 is thus related to the oxidation of the inner titanium nitride grains, and is primarily controlled by the inward diffusion of oxygen through $\mathrm{TiO}_{2}$, which corresponds to the second mode of the model (stage 2). The deceleration of the growth of this layer corresponds to the transient stage (stage 3 ) separating the second (stage 2) and third (stage 4) modes.

After $50 \mathrm{~h}$ of oxidation at $1150^{\circ} \mathrm{C}$, layers 1 and 3 have reached a constant thickness, and only layer 2 continues to grow. The latter is formed by a progressive consumption of layer 3 . The fact that the thickness of layer 3 remains constant after 50 hours of oxidation means that its formation at the $\mathrm{I} 3$ interface (interface between layer 3 and the core material) and its consumption at the I 2 interface (interface between layers 2 and 3) take place at the same rate and that they are controlled by the same mechanism. This oxidation stage thus corresponds to the third oxidation mode (stage 4), controlled by the diffusion of oxygen through the silica, which is the main component of layer 2 .

The sintering additives contained in the material $\left(\mathrm{Al}_{2} \mathrm{O}_{3}, \mathrm{Y}_{2} \mathrm{O}_{3}\right)$ affect the morphology and composition of the oxide layer. Indeed, an outward diffusion of aluminum and yttrium, initially present in the intergranular phase, has been observed according to WDS analyses (Figs. 2 and 7). However, we have assumed in the present oxidation model that these phenomena have a negligible effect on the mechanisms controlling the oxidation process. We are now going to discuss the way these additives can affect the model stages.

Some effects of the intergranular phase, containing elements issued from the sintered aids, on the oxidation process have been reported in the literature for $\mathrm{Si}_{3} \mathrm{~N}_{4}$-based materials. In this phase, aluminum and yttrium species can react with $\mathrm{SiO}_{2}$ to form crystalline compounds (mullite, yttrium silicates), which can crack the oxide layer. ${ }^{30,31}$ When the intergranular phase is vitreous, the aluminum and yttrium species diffuse rapidly toward the surface, releasing oxygen, which can lead to an internal oxidation of $\mathrm{Si}_{3} \mathrm{~N}_{4}$ grains. ${ }^{32,34}$ Some species can also dissolve in silica, leading to a decrease in viscosity. ${ }^{30,33}$ Thus, oxygen can quickly diffuse through the oxide, the crystallization of vitreous oxide is favored, and nitrogen forms bubbles more easily, which can burst on the surface.

In the case of the $\mathrm{Si}_{3} \mathrm{~N}_{4}-\mathrm{TiN}$ composite, the effect of the sintering aids should be weak during the first two stages of the oxidation described in the model, because they primarily involve oxidation of the titanium nitride phase. The third and fourth oxidation stages involve oxidation of both the titanium nitride and $\mathrm{Si}_{3} \mathrm{~N}_{4}$ phases, so the intergranular phase may have an effect. Crystalline compounds (mullite and yttrium silicates or titanates), issued from reactions between aluminum and yttrium species of the intergranular phase and silicon and/or titanium oxides, were observed in the silica-rich sublayer. They may have affected the diffusion rate of oxygen through this layer. However, those crystals are rare and isolated and are surrounded by vitreous silica, so the risk of crack formation caused by growth stresses is small. They may slightly decrease the diffusion rate of oxygen through $\mathrm{SiO}_{2}$, because the diffusion through crystals is slower than through a vitreous phase. The crystals can have a stronger effect if vitreous oxide crystallizes, which is favored by aluminum dissolution in $\mathrm{SiO}_{2}$. Cracks can then be formed during the growth of mullite and yttrium silicates or titanates crystals. However, this phenomenon is observed only at high temperatures or for long oxidation duration at $<1200^{\circ} \mathrm{C} .{ }^{30}$ More important is the effect of dissolved aluminum in $\mathrm{SiO}_{2}$, which leads to an increase in the diffusion rate of oxygen through vitreous oxide, which has a lower viscosity. The formation and growth of bubbles in the sublayer confirms the low viscosity of this vitreous phase.

However, these phenomena do not significantly modify the main oxidation mechanisms, even if they change their rate. The model is valid as long as the $\mathrm{SiO}_{2}$ phase remains vitreous. When silica crystallizes, cracks may appear because of crystalline growth stresses, and oxygen can diffuse through the bulk material via this path.

\section{Conclusion}

This paper is a contribution toward a better understanding of the oxidation behavior of silicon nitride-titanium nitride composites. Microstructural and kinetics studies of the oxidation of such a material were conducted initially. Taking into account the results of these studies and bibliographical data, an oxidation model of the material at $1150^{\circ} \mathrm{C}$ has been proposed.

Three oxidation modes, controlled by distinct diffusion mechanisms, take place successively:

(1) At an early stage, the oxidation process is controlled by the diffusion of titanium through $\mathrm{TiO}_{2}$, which is oxidized at the oxide/gas interface, resulting in the formation of a continuous rutile $\left(\mathrm{TiO}_{2}\right)$ layer at the outer surface. The outward diffusion of titanium leads to the formation of porosity in the titanium nitride grains of the sublayer. These cavities lead to a reduction in the available surface for titanium diffusion, and thus a deceleration of the oxidation rate. 
(2) The oxidation kinetics become gradually controlled by the oxygen diffusion through the rutile and through the cavities of the sublayer, where it reacts with the internal titanium nitride particles and the $\mathrm{Si}_{3} \mathrm{~N}_{4}$ phase.

(3) For greater oxidation times, the silicon nitride phase oxidation leads to the formation of a continuous layer of amorphous silica under the surface $\mathrm{TiO}_{2}$ layer. The dominating process becomes the diffusion of oxygen through this $\mathrm{SiO}_{2}$-rich phase.

These three modes are separated by transient stages, during which the rate of the dominating mechanism gradually decreases. The model allows us to understand the microstructural characteristics of the oxides formed at $1150^{\circ} \mathrm{C}$.

\section{Acknowledgment}

The authors would like to thank Dr. C. Colin (Ecole des Mines de Paris, France) for his participation in the WDS investigations.

\section{References}

${ }^{1}$ K. H. Suzuki, H. Yoshida, and S. Yamaguki, "Ceramic Heater and a Method for Its Production," U.S. Pat. No. 4613 455, 1986.

${ }^{2}$ C. H. Murtry, W. D. G. Boecker, S. G. Seshadri, J. S. Zanghi, and J. E. Garnier, "Microstructure and Material Properties of $\mathrm{SiC}-\mathrm{TiB}_{2}$ Particulate Composites," Am. Ceram. Soc. Bull., 66, 325 (1987).

${ }^{3}$ M. Higuchi, M. Miyake, H. Kakeuchi, and E. Kamjo, "Electrically Conductive Sintered Compact of $\mathrm{Si}_{3} \mathrm{~N}_{4}$ Machinable by Electrical Discharge Machining and Process of Producing the Same," U.S. Pat. No. 4659 508, 1987.

${ }^{4}$ C. Martin, P. Mathieu, and B. Cales, Electrical Discharge Machinable Ceramic Composites, Proceedings of Symposium on Ceramic Materials Research, European Materials Research Society Spring Conference (Strasbourg). Edited by R. J. Brook. European Materials Research Society, Strasbourg, France, 1988.

${ }^{5} \mathrm{~A}$. Bellosi, S. Guicciardi, and A. Tampieri, "Development and Characterization of Electroconductive $\mathrm{Si}_{3} \mathrm{~N}_{4}-\mathrm{TiN}$ Composites," J. Eur. Ceram. Soc. 9, 83-93 (1992).

${ }^{6} \mathrm{~J}$. Desmaison, P. Lefort, and M. Billy, "Oxidation Mechanism of Titanium Nitride in Oxygen," Oxid. Met., 13 [6] 505-17 (1979).

${ }^{7}$ M. Billy, "Reactivity in Nitrogen Ceramics"; pp. 45-60 in Science of Ceramics14th International Conference (Canterbury, U.K., 1987). The Institute of Ceramics, Stoke-on-Trent, Straffordshire, U.K.

${ }^{8}$ A. Bellosi, A. Tampieri, and Y. Z. Liu, "Oxidation Behaviour of Electroconductive $\mathrm{Si}_{3} \mathrm{~N}_{4}-\mathrm{TiN}$ Composites," Mater. Sci. Eng., A, A127, 115-22 (1990).

${ }^{9}$ Y. G. Gogotsi and F. Porz, "The Oxidation of Particulate-Reinforced $\mathrm{Si}_{3} \mathrm{~N}_{4}-\mathrm{TiN}$ Composites," Corros. Sci., 33 [4] 627-40 (1992).

${ }^{10} \mathrm{~F}$. Peni, J. Crampon, and R. Duclos, "On the Morphology and Composition of the Oxidized Layer in $\mathrm{Si}_{3} \mathrm{~N}_{4}$-based Materials," Mater. Sci. Eng., A, A163, 5-7 (1993).

${ }^{11}$ Y. G. Gogotsi, F. Porz, and G. Dransfield, "Oxidation Behavior of Monolithic TiN and TiN Dispersed in Ceramic Matrices," Oxid. Met., 39 [1/2] 69-91 (1993).

${ }^{2}$ P. Lefort, J. Desmaison, and M. Billy, "Oxydation du Nitrure de Titane par l'Oxygène: Comportement du Nitrure TiN ${ }_{0.95}$ Pulvérulent," C. R. Acad. Sci., C285, 361-69 (1977)

${ }^{13}$ P. Lefort, J. Desmaison, and M. Billy, "Cinétique d'Oxydation du Nitrure de Titane: Comportement de Plaquettes de Nitrure $\mathrm{TiN}_{0.91}$ en Atmosphère d'Oxygène," J. Less-Common Met., 60, 11-24 (1978).
${ }^{14}$ Y. G. Gogotsi, F. Porz, and V. P. Yaroshenko, "Mechanical Properties and Oxidation Behavior of $\mathrm{Al}_{2} \mathrm{O}_{3}-\mathrm{AlN}-\mathrm{TiN}$ Composites," J. Am. Ceram. Soc., 75 [8] 2251-59 (1992)

${ }^{15}$ A. Tampieri, E. Landi, and A. Bellosi, "The Oxidation Behaviour of Monolithic TiN Ceramic,” Br. Ceram. Trans. J., 90, 194-96 (1991).

${ }^{16} \mathrm{H}$. Ichimura and A. Kawana, "High-Temperature, Oxidation of Ion-Implanted TiN and TiAlN Films," J. Mater. Res., 8 [5] 1093-1100 (1993).

${ }^{17}$ P. Kofstad, High Temperature Corrosion, pp. 289-98. Elsevier Applied Science Publishers Ltd., Oxford, U.K.,1988.

${ }^{18}$ Y. Park and D. P. Butt, "Composition, Dependence of the Kinetics and Mechanisms of Thermal Oxidation of Titanium-Tantalum Alloys," Oxid. Met., 51 [5/6] 383-402 (1999)

${ }^{19}$ R. J. Hanrahan and D. P. Butt, "The Effects of Nitrogen on the Kinetics and Mechanisms of Oxidation of Titanium-Tantalum Alloys," Oxid. Met., 48 [1/2] 41-58 (1997)

${ }^{20}$ D. J. Choi, D. B. Fischbach, and W. D. Scott, "Oxidation of Chemically-Vapor Deposited Silicon Nitride and Single-Crystal Silicon,” J. Am. Ceram. Soc., 72 [7] 1118-23 (1989)

${ }^{21}$ H. Du, R. E. Tressler, K. E. Spear, and C. G. Pantano, "Oxidation Studies of Crystalline CVD Silicon Nitride," J. Electrochem. Soc., 136 [5] 1527-36 (1989).

${ }^{22} \mathrm{H}$. Du, R. E. Tressler, and K. E. Spear, "Thermodynamics of the Si-N-O System and Kinetic Modeling of Oxidation of $\mathrm{Si}_{3} \mathrm{~N}_{4}$, J. Electrochem. Soc., 136 [11] 3210-15 (1989)

${ }^{23}$ H. Du, R. E. Tressler, K. E. Spear, and M. Wang, "Annealing Studies of Coupled $\mathrm{Si}_{3} \mathrm{~N}_{4}$ and $\mathrm{SiO}_{2}$ Films," J. Mater. Sci. Lett., 8, 1341-43 (1989).

${ }^{24}$ L. U. J. T. Ogbuji and J. L. Smialek, "Evidence from Transmission Electron, Microscopy for an Oxinitride Layer in Oxidized $\mathrm{Si}_{3} \mathrm{~N}_{4}$," J. Electrochem. Soc., 138 [10] L51-L53 (1991).

${ }^{25}$ D. P. Butt, D. Albert, and T. N. Taylor, "Kinetics of Thermal Oxidation of Silicon Nitride Powders," J. Am. Ceram. Soc., 79 [11] 2809-14 (1996).

${ }^{26}$ K. L. Luthra, "A Mixed Interface Reaction/Diffusion Control Model for Oxidation of $\mathrm{Si}_{3} \mathrm{~N}_{4}$, , J. Electrochem. Soc., 138 [10] 3001-3007 (1991).

${ }^{27}$ L. U. J. T. Ogbuji and S. R. Bryan, "The $\mathrm{SiO}_{2}-\mathrm{Si}_{3} \mathrm{~N}_{4}$ Interface, Part I: Nature of the Interface," J. Am. Ceram. Soc., 78 [5] 1272-78 (1995).

${ }^{28}$ L. U. J. T. Ogbuji, "The $\mathrm{SiO}_{2}-\mathrm{Si}_{3} \mathrm{~N}_{4}$ Interface, Part II: $\mathrm{O}_{2}$ Permeation and Oxidation Reaction," J. Am. Ceram. Soc., 78 [5] 1279-84 (1995).

${ }^{29}$ B. W. Sheldon, "Silicon Nitride Oxidation Based on Oxynitride Interlayers with Graded Stoichiometry," J. Am. Ceram. Soc., 79 [11] 2993-96 (1996).

${ }^{30} \mathrm{M}$. H. Lewis and P. Barnard, "Oxidation Mechanism in Si-Al-O-N Ceramics," J. Mater. Sci., 15, 443-48 (1980).

${ }^{31}$ L. Wang, C. He, and J. G. Wu, "Oxidation of Sintered Silicon Nitride Materials"; pp. 604-11 in 3rd International Symposium on Ceramic Materials and Components for Engines (Las Vegas, NV, Nov. 27-30, 1988). American Ceramic Society, Westerville, $\mathrm{OH}$.

${ }^{32} \mathrm{D}$. R. Clarke and F. F. Lange "Oxidation of $\mathrm{Si}_{3} \mathrm{~N}_{4}$, Alloys: Relation to Phase Equilibria in the System $\mathrm{Si}_{3} \mathrm{~N}_{4}-\mathrm{SiO}_{2}-\mathrm{MgO}$," J. Am. Ceram. Soc., 63 [9-10] 586-93 (1980)

${ }^{33}$ C. O. Meara and J. Sjoberg, "Transmission Electron Microscopy Investigation of the Oxidation of Hot Isostatically Pressed Silicon Nitride with and without Sintering Aids," J. Am. Ceram. Soc., 80 [6] 1491-500 (1997).

${ }^{34}$ G. Ziegler, J. Heinrich, and G. Wötting, "Review: Relationships between Processing, Microstructure, and Properties of Dense and Reaction-Bonded Silicon Nitride," J. Mater. Sci., 22, 3041-86 (1987).

${ }^{35} \mathrm{~V}$. K. Sarin, "On the $\alpha$ to $\beta$ Phase Transformation in Silicon Nitride," Mater. Sci. Eng. A, A105/106, 151-59 (1988).

${ }^{36} \mathrm{~K}$. Oda and T. Yoshio, "Properties of $\mathrm{Y}_{2} \mathrm{O}_{3}-\mathrm{Al}_{2} \mathrm{O}_{3}-\mathrm{SiO}_{2}$, Glasses as a Model System of Grain Boundary Phase of $\mathrm{Si}_{3} \mathrm{~N}_{4}$ Ceramics (Part 1): Physical Properties," J. Ceram. Assoc. Jpn., Int. Ed., 97, 1502-507 (1989).

${ }^{37}$ D. M. Mieskowski, T. E. Mitchell, and A. H. Heuer, "Bubble Formation in Oxide Scales on SiC,"J. Am. Ceram. Soc., 67 [1] C17-C18 (1984). 